\title{
Theorizing Learning through Complexity: An Educational Critique
}

\author{
A Response to Ton Jörg's Programmatic View
}

\section{GERT BIESTA}

The Stirling Institute of Education, University of Stirling, (UK)

Ton Jörg has done a magnificent job in outlining a new way to understand the dynamics of learning and, more specifically, learning that results from "peer-to-peer" and "face-toface" interaction. Jörg takes inspiration from Vygotsky's ideas on the role of interaction in the development of higher mental functioning and uses ideas from complexity to highlight the nonlinear and "generative" character of human interaction. He introduces the notion of "bootstrapping" to better understand the dynamics of such processes and ends up with a view of learning as a process of "co-creating each other in progressive experience." Jörg's main "target," so to speak, consists of linear and non-generative ways of understanding learning, education and human interaction. Jörg, on the other hand, presents learning and development as radically open processes and argues that because of their radically open character we should (re-)organize our educational practices so that they will facilitate such open, undetermined and generative forms of learning and interaction.

I agree with most of what Jörg has to say about the non-linear character of human interaction and the generative dynamics of such processes. In my own work, inspired by Dewey, Mead, Derrida and complexity, I have come to similar conclusions about human interaction and communication (see, e.g., Biesta, 2005; in press; Vanderstraeten and Biesta, 2006). From this angle the strong convergence between the traditions upon which Jörg builds his ideas and the insights from pragmatism and deconstruction is interesting, although the absence of any references to pragmatism is also remarkable. This is 
particularly so in light of Jörg's claims that "(t)he notion of interaction is rather new in the history of our sciences" and that "(n)o adequate theory of (human) interaction has so far been developed," as I would argue that Dewey's philosophy of experience and his work on transaction and communication provides a pretty adequate theory of human interaction; a theory, moreover, which is particularly adequate for addressing questions concerning learning and education. Similarly I would say that Jörg is a bit too quick in concluding that the "dominant choice" within the development of the social sciences has been that of "becoming a copy of the natural sciences," as there is a whole tradition from Dilthey to Habermas and beyond that has articulated a distinctively different programme for the social sciences (see, e.g., Habermas, 1970). But the point I wish to make in this response is not about the need to include pragmatism, hermeneutics or critical theory in the discussion, as what counts most for me is the strength and quality of the argumentation, not the particular theoretical resources being utilized.

The point I wish to develop in this response has to do with the fact that although I tend to agree with most of what Jörg has to say, I do not think that what he is saying (already) amounts to a theory of education, and I even have doubts about the extent to which it can count as a theory of learning. This does not mean that I think that Jörg's ideas are invalid. On the contrary. I simply want to suggest that there is a need to widen the picture in order to understand where, how and in what ways Jörg's views about learning and interaction make sense. To do this I want to focus on two issues: education and learning.

From my perspective - which I would characterize as that of an educationalist - I find that Jörg says relatively little about education. Quite often he writes about "learning and education," suggesting that the two are actually almost the same. "Education" also seems to stand for "formal education," i.e., schooling. And then there are some more intriguing comments, such as the claim that Vygotsky's theory of development can be taken as "a full theory of education," or the suggestion that "generative learning through communicative human interaction within personal relationships" should be "a norm for learning and development in education." In my view, however, learning - alone or with others - in itself does not constitute education. For there to be education, we need a combination of three elements: purpose, process and content. If we have process and content - someone learning something - we have learning, but not education. This is because education is not about any learning, but about learning that is "framed" in relation to particular "outcomes" - which still leaves the question entirely open as to what these "outcomes" should be and who should define them (the student, the teacher, or the state, to name but a few options). This is why the language of learning is in itself not (yet) a language of education (see Biesta, 2004; 2006). When we conflate the two, we lose sight of the fact that "educational learning" is always learning "framed" in relation to particular purposes (see also Osberg \& Biesta, 2008).

This is the main reason why I can read Jörg's contribution as a new way to theorize learning, but not as a (new) way to theorize education. Jörg, to put it differently, helps us to understand part of (see below) the process element of the educational "triad" in a new way, but that, in itself, is not enough for a theory of education. To the extent to 
which Jörg does articulate a theory of education - or perhaps we should call it an educational programme - I would argue that he comes close to committing what in the philosophical literature is known as the naturalistic fallacy, i.e., the unwarranted step from "is" to "ought." Jörg's case for an "education of the unexpected," if I understand him correctly, is based on a line of thinking which says that because learning through interaction is open and generative this is what education should make possible and promote. But the "should" in this argument does not necessarily follow from the "is." After all, one could as well argue that because learning through interaction is open and generative we should organize in a way that reduces the complexity and unpredictability of learning, because otherwise the chances will not be very high that students will learn what they are supposed to learn (see also Biesta 2008). In other words: the question which forms of learning - and of student activity more generally - are desirable cannot be answered through an analysis of the process of learning, but needs to be approached from the angle of purpose, i.e., the question as to what learning is for.

From this angle it is also not entirely clear why Jörg emphasizes the role of interaction, particularly in the form of peer-to-peer interaction. There is, of course, nothing wrong with peer-to-peer interaction as a way to organize student activity, but there is also nothing necessary about peer-to-peer interaction. Students can also learn from reading books, surfing the internet, construction and experiment, listening to a teacher, daydreaming, and so on. It is, therefore, one thing to highlight what is special about learning through interaction, but it is quite another to make this into the "standard" for education (or even for learning). If I understand Jörg correctly, the main inspiration for his emphasis on interaction comes from Vygotsky and, to a lesser extent, from Bruner. But it is important to bear in mind that for Vygotsky the importance of interaction had to do with the development of higher mental functioning. If this is what one is after in education, then it makes sense - if one believes that Vygotsky is right, of course - to organize educational processes interactively. But cognitive development - or growth, to use the Deweyan term that I would prefer in this context - is only one aspect of what matters or might matter in education. This suggests that if one's aim is to promote growth of "lower" mental functioning or growth in non-cognitive domains such as the affective or the motor domain - it may well be that interaction is not the preferred, optimal or most effective way to organize learning.

From the angle of Bruner the issue of interaction is a slightly different one, as from such an angle the focus is not exclusively on the promotion of higher mental functioning but on the acquisition of and access to culture more generally. Here one could argue and this is a key insight in the work of Dewey and Mead (see, e.g., Biesta 2005; in press) - that the only way in which we can access existing cultural meanings and cultural tools is through participation in the practices in which these tools and meanings "mean" something. This would suggest that participation has to play a role in education (although it doesn't suggest that participation is the only way in which learning should be organized, because once one has gained access to aspects of culture - e.g., written language - learning can begin to utilize much more individuals "modes" such as learning through reading and learning through writing). 
This does, however, raise a further issue which has to do with the role of the teacher - and this is the reason why I suggested above that Jörg focuses only on a part of the process element of the educational "triad," viz. the part that has to do with how students learn through interaction with other students. There are two related issues here. One is that Jörg mainly seems to talk about symmetrical relationships, i.e., relationships between peers. He writes, for example, about "'learners who bootstrap each other' in subcommunities of mutual learners" (this issue, p. 12). Such an account is, of course, adequate if we have processes of experiential and discovery learning in mind. But the point is that in educational settings students are there to learn something - mathematics, French, car mechanics, social care, brain surgery, dance, philosophy, hair dressing, plumbing, writing, citizenship, and so on - rather than just anything. This is why the teacher is not simply a "fellow-traveller" or a "facilitator of learning." The teacher is the one who presents and represents what is to be learned and is also the one who is involved in the judgments about whether students have been successful in their learning. The teacher thus introduces an asymmetrical element in the educational process, and this is one of the main reasons why "educational learning" is radically different from collective, interactive explorative learning. One question, therefore, is how we can bring the position of the teacher into the picture. The other question is how we can take the "content" of learning - in the broad sense of the word - into account.

It is remarkable that Jörg says very little about the question of content, that is, the question of the "what" of learning. "Learning," for Jörg, mainly seems to be a process, and it seems to matter little what is learned or what the quality of the learning is. While this may be adequate in order to understand the dynamics of the process, it is not enough in the context of education where questions about what is learned, and about how well it is learned, are always of crucial importance. What is also remarkable is that Jörg seems to assume that learning is one-dimensional, i.e., that for our theorizing of learning it does not matter what the learning is of and what it is for. For Jörg learning seems to be the same process irrespective of whether it is learning for memorizing, learning for understanding, learning for emancipation, learning for mastery of a skill, learning for moral growth, learning for political action, and so on. This may well be what Jörg would want to argue for, but it remains only implicit in his theory of learning, which means that for educators who want to utilize Jörg's ideas there is relatively little guidance as to how this might work in such radically different areas as liberal education or the education of plumbers. One way to view Jörg's contribution is as a theory of interactive experiential discovery learning. There is, of course, a place for such learning in many educational processes, but it is unlikely that this will be the be all and end all of it.

This brings me to a second, more theoretical issue which has to do with the fact that Jörg nowhere seems to provide us with a definition of learning. This, again, is remarkable because in order to theorize learning it would be helpful to know what the theorizing is about and what it is referring to, not in the least because Jörg argues without developing the point in any detail - that "learning itself is a construction invented by mankind." It is in relation to this that I wish to point at a rather curious 
aspect of the notion of learning. One of the broadest definitions of learning is one that sees learning as any more or less permanent change that is not the result of maturation. Such a definition highlights the fact that learning is about change and also that learning is in some way connected to the "effects" of our interactions with our "environments," natural and social. I do not think that Jörg would object to this definition, not in the least because it encompasses the interactive and experiential dimensions of learning. But the difficulty with this definition is that it may prove rather difficult if not impossible to separate out from any change that happens, those aspects that are the result of maturation and those that are the result of experience. This is why it is more likely that when we use the word "learning" - for example when we say that someone has learned something - we are actually making a judgment about particular change, indicating that we find the change that has resulted from some kind of process or activity desirable. When we describe something as "learning" we are, therefore, in fact making a judgment about what we consider to be good or desirable change. This implies that "learning" is not a descriptive term - it is not a noun - but rather an evaluative term (which may explain some of the difficulties with attempts to define learning).

But if it is the case that "learning" is a retrospective judgment, something we judge after the event, so to speak, it means that when we are engaged in certain activities we cannot know yet whether they will result in learning. To refer to those activities as learning - as is often done, e.g., in a phrase such as learning through interaction - is therefore a mistake. We can refer to such activities as activities, or with words such as "studying" or "student work," but it is only on the basis of a retrospective judgment that we can use the word "learning." If these observations make sense, and I offer them in the spirit of Ton Jörg's attempt to escape from what he refers to as "an imprisonment of meaning" - an imprisonment, as I see it, in certain taken-for-granted ways of thinking and talking - then it means that in the strict sense, a theory of learning is an impossibility. We can have theories of change and theories of activity but whether they amount to learning always involves a retrospective judgment. This is what I had in mind when I suggested that I doubted whether Jörg's ideas would qualify as a theory of learning. This, again, is not because I would argue that Jörg's ideas are not valid; it is simply because I think that what Jörg is theorizing is a particular form of (student) activity and a particular way to understand change in relation to (student) activity. The extent to which all this amounts to and is relevant for the discourse of learning is a matter of judgment - judgment about what the desirable outcomes of such activity are.

I conclude, therefore, that Ton Jörg has provided us with a fascinating set of insights into the dynamics of peer-to-peer interaction and its outcomes and into the potential significance of theorizing such processes for our understanding of learning. That this may not be a theory of learning in the strict sense is, as I have tried to make clear in this response, less of a problem than the question to what extent Jörg's theorizing can actually be seen as a theory of education. 


\title{
References
}

Biesta, G.J.J. 2004. Against learning. Reclaiming a language for education in an age of learning. Nordisk Pedagogik 23: 70-8

Biesta, G.J.J. 2005. “George Herbert Mead and the theory of schooling." In Pragmatism and education, edited by D. Troehler \& J. Oelkers, 117-132. Rotterdam: Sense Publishers.

Biesta, G.J.J. 2006. Beyond learning. Democratic education for a human future. Boulder, Co.: Paradigm Publishers.

Biesta, Gert 2008. Five theses on complexity reduction and its politics. A paper presented at the Annual Meeting of the American Educational Research Association, New York, 24-28 March 2008.

Biesta, G.J.J. (in press). "Pragmatism's contribution to understanding learning-in-context." In Contexts, communities and networks, edited by R. Edwards, G.J.J. Biesta \& M. Thorpe. London: Routledge.

Habermas, J. 1970. Zur Logik der Sozialwissenschaften. Frankfurt am Main: Suhrkamp.

Osberg, D.C. \& Biesta, G.J.J. 2008. The emergent curriculum: Navigating a complex course between unguided learning and planned enculturation. Journal of Curriculum Studies 40(3), 313-328.

Vanderstraeten, R. \& Biesta, G.J.J. 2006. How is education possible? A pragmatist account of communication and the social organisation of education. British Journal of Educational Studies 54(2), 160-174.

\begin{abstract}
About the Author
Gert Biesta (www.gertbiesta.com) is Professor of Education and Director of Postgraduate Research at The Stirling Institute of Education, University of Stirling, Stirling, FK9 4LA, Scotland, UK. His research focuses on the theory and philosophy of education with a particular interest in questions about education and democracy. He takes inspiration from pragmatism (Mead, Dewey), Continental philosophy (Derrida, Levinas), Continental educational theory and North-American curriculum theory. He can be contacted at the following email address: gert.biesta@stir.ac.uk.
\end{abstract}

(C) Copyright 2009. The author, GERT BIESTA, assigns to the University of Alberta and other educational and non-profit institutions a non-exclusive license to use this document for personal use and in courses of instruction provided that the article is used in full and this copyright statement is reproduced. The author also grants a non-exclusive license to the University of Alberta to publish this document in full on the World Wide Web, and for the document to be published on mirrors on the World Wide Web. Any other usage is prohibited without the express permission of the authors. 0 